\title{
Twenty Years of Law Journal Publishing: A Comparative Analysis of International Publication Trends
}

\author{
László Christián ${ }^{1}$ • Gergő Háló ${ }^{2}$ · Márton Demeter ${ }^{1}$
}

Published online: 9 February 2022

(C) The Author(s) 2022

\begin{abstract}
The analyses of publishing trends are gaining importance across various disciplines, yet we have limited knowledge on the extent to which international publication processes have developed within the field of legal studies. Based on bibliometric and network analyses focusing on the past two decades, our research investigates publishing and internationalization processes in the pool of Scopus-indexed law journals, as well as the publication patterns of the most prolific Law scholars. Results indicate that most legal studies journals are concentrated in the hands of a few global publishers and university presses, and, while the number of Scopus-indexed law journals are high, the level of internationalization is relatively low. Consequently, further efforts are prompted to enhance geographical diversity and increase the level of international collaboration.
\end{abstract}

Keywords Legal studies $\cdot$ Publishing trends $\cdot$ Law journals $\cdot$ Scopus $\cdot$ International collaboration

\section{Introduction}

As scientific problem-solving increasingly appear to be benefitting from an international scope-that is, attention given to different socio-cultural, economic, and political contexts in a transperspectival manner, and ideas being disseminated across state lines - a growing number of authors from various disciplines necessitates the internationalization of academia (e.g., [29, 31, 35]. Accordingly, internationalizing local research is becoming an important policy target in most countries [9, 22] with researchers increasingly being evaluated via criteria that distinctly promotes international publishing, that is most of the time, publishing in dominant outlets of the

Márton Demeter

Demeter.Marton@uni-nke.hu

1 National University of Public Service, 2 Ludovika Square, 1083 Budapest, Hungary

2 Corvinus University of Budapest, Budapest, Hungary 
mainstream Anglo-American academic world [19, 28]. Notwithstanding, the extent to which these internationalization processes has so far been realized is often under scrutiny, and the outlook is rarely unequivocal [20].

Such uncertainties mark the internationalization progresses of legal fields. Social sciences, in general, seem to be particularly prone to conceal Anglo-American dominance [23] while - at the same time-assume the universality of social knowledge production [17, 18, 42]). As Faraldo-Cabana and Lamela [26, p. 154] points out, law-related fields, then, are "only beginning to feel concerned by the admissibility of [their] claims to universality" (e.g., [1, 5, 8, 11, 12, 30, 38, 39, 50]. However, internationalization of the discipline appears more and more desirable for several reasons: it increases the external validity of theory,aids the establishment of global "best practice"; and-as crime becomes increasingly transnational—reduces pockets of impunity by harmonizing definitions and procedures [5].

One of the main problems when indicating the level of internationality in lawrelated academic fields is the scarcity of relevant literature [26]. The aim of this study, therefore, is to expand this line of research via bibliometric and network analytic means. In 2007, Rosemary [5, p. 424] called out her fellow academics in criminology to reconceptualize the discipline in order to avoid falling into American isolationism: "future research will hopefully show that we have made strides in the twenty-first century to do so." Given the persistent advocacy for greater internationalization within criminological fields [3, 5-7, 41, 50], the present research, then, is also to confirm if said hopes of hers turned out to be well-founded.

\section{Literature review}

Although the tradition of bibliometrics - that precedes scientific applicationsappears to be historically inseparable from the legal world [43, 44], the literature of bibliometric studies concerning the topic of internationality of academic legal research is relatively scarce compared to other fields, for instance, geographics [4, 27], information science [48], international relations [40], or psychology [2, 10]. The existing literature typically focuses on the field's internationality as indicated either by the most influential scholars $[15,16,25]$ or by specific journals $[26,32$, 35-37].

One relatively established line of research, typically following Cohn and Farrington's [13] original analysis on the top cited scholars in the field of criminology, have successfully — on multiple occasions, yet often in a subsidiary mannerrecorded the affiliation country of some of the most influential criminologists and of the authors publishing in the most influential criminology journals, only to find serious disproportions from time to time [15, 16, 25]. Cohn and Farrington [15], for instance, in order to identify the most-cited scholars of the field examined all articles published in 1995 in twenty highly influential criminology and criminal justice journals (i.e., 10 American, 10 international). They noted that $68 \%$ of the authors of these publications were affiliated in the US, whilst authors publishing in the American journals were $82 \%$ US-based, which also meant that only $52 \%$ of the authors publishing in international outlets were non-American by affiliation. Fabianic [25], 
building on previous compilations (i.e., [13, 14, 49], examined the educational background of the top cited authors in criminal justice. His results showed that out of eighty highly influential scholars, only four got terminal degrees outside of the US (i.e., Emile Durkheim at Sorbonne, David P. Farrington at Cambridge University, John Hagan at the University of Alberta, and Jock Young at the London School of Economics). Most recently, Cohn and Iratzoqui [16] pointed out that nine out of the ten most cited scholars in five major international criminology journals between 2006 and 2010 were American by affiliation. Their results are especially unsettling when considering that the journals involved in the study were primarily international outlets, such as the British Journal of Criminology, the Australian and New Zealand Journal of Criminology, the Canadian Journal of Criminology and Criminal Justice, and the European Journal of Criminology. The study also indicated serious disproportions considering the national affiliations of authors; in Criminology, a leading journal of the field, 90\% of all articles published between 2006 and 2010 were written by American authors, and an apparent Anglo-Saxon dominance manifested in the publishing patterns throughout almost all journals, with the humble exception of European Journal of Criminology, which, however, compared to the other outlets examined, also happened to be admittedly less prestigious at the time [16, p. 5]. Notwithstanding, the indications of the abovementioned studies are most often restricted by the small number of journals included. Furthermore, as Faraldo-Cabana and Lamela [26, p. 153] points out, due to their primary aim to assess scholarly influence, the somewhat incidental measures of affiliations involved tend to poorly reflect internationality on more general levels ${ }^{1}$ (e.g., internationality of journals).

The rising advocacy for greater internationalization within criminological fields $[5,50]$ have recently motivated several efforts to empirically assess the internationality of criminology and criminal justice. Accordingly, compared to the abovementioned studies, we find more direct measures of internationality in the works of Barberet [5], Kim and Merlo [33], Kim et al. [32, 35, 36], Faraldo-Cabana and Lamela [26], and Messner [37].

One of the first works to take such efforts was Barberet's [5] content analysis of 8287 presentations at the annual conferences of the American Society of Criminology - a self-proclaimed international organization-in the 1990s. Her results showed that, despite some minor progress during the time covered, criminological fields in the US were still decidedly US-centric by national affiliation of the authors and mostly consisting of single country (i.e., non-comparative) analyses. Consequently, Barberet necessitated the reconceptualization of the discipline to avoid an American isolationism and to promote internationality [5, p. 424]. In a similarly designed study, Kim and Merlo [33] analyzed 3738 presentations at the

\footnotetext{
1 Similar limitations arise when considering a somewhat outdated line of studies that measure institutional influence in the fields of criminology and criminal justice [24, 45-47]. Most of these studieswith the primary aim to assess and compare American institutions-excluded foreign affiliations by design (e.g., [47]. Observations, such as those of Sorensen [45], that over $80 \%$ of all the authors in each journal he examined - that is, the most influential journals in the field - resided in the United States, however, are nonetheless indicative of serious disproportionalities.
} 
European Society of Criminology conferences between 2001 and 2010, as well as 171 articles published in the European Journal of Criminology between 2004 and 2010. Their content analysis indicated that most presenters $(85.6 \%)$ were affiliated in Europe; and their presentations were Europe-centric. Furthermore, out of the 3738 presentations, only 57 drew comparisons between countries in a transnational partnership, with only three comparing two or more countries where at least one of them was outside of Europe. Similarly, most articles published in the European Journal of Criminology focused on a single country in Europe and were authored by European affiliated scholars. Isolationism, therefore, is not a threat that seem to only apply to the US.

Similarly, various studies conducted by Kim and colleagues set out to indicate the progress of internationalization within criminology and criminal justice as presented on the levels of policing [36], juvenile justice [32] and women specialty [35]. Kim et al. [36] analyzed 1123 papers published in the three major policing journals of Police Quarterly, Policing: An International Journal of Police Strategies \& Management, and Policing during the period of 2000-2013 to assess the prevalence of articles concerning policing in East Asian countries, a region accounting for one-fifth of the world's population. Their study found that only about $3.4 \%(n=38)$ of the articles published concerned East Asian policing. Furthermore, almost half of these publications $(n=17)$ were written solely by US-affiliated authors, and only about one third (26 out of 78) of the editorial board members of the journals were non-US affiliated [35]. In another study, focusing on four major US juvenile justice journals (Juvenile and Family Court Journal, Journal of Juvenile Justice, UC Davis Journal of Juvenile Law and Policy, and Youth Violence and Juvenile Justice), Kim et al. [32] examined 567 papers published between 2000 and 2013 to assess the prevalence of international research, and indicated that only very few of them $(n=17)$ dealt with juvenile justice issues in nations other than the US. Moreover, out of 85 editorial board members at the journals investigated, only two were affiliated outside of the US [35]. After that, Kim et al.'s [35] analysis of leading women specialty journals (Feminist Criminology, Violence Against Women, and Women and Criminal Justice) between 2010 and 2016, is able to provide some grounds for optimism concerning the internationalization of criminology and criminal justice. Results of this study indicate both non-trivial representation of editorial board members affiliated outside the US (ranging from 9 to 23\%), and high levels of transnational collaborations $(28.5 \%$ of the articles examined were co-authored by scholars with different national affiliations). For comparison, in the above-mentioned study of ASC conference presentations by Kim and Merlo (2014), these kinds of collaborations were reflected only in $1.3 \%(n=6)$ of the total sample.

Although being limited to specific areas of criminology and criminal justice (i.e., policing, juvenile justice, and women specialty) — and thus unable to provide a general overview on the field-the various analyses by Kim and her colleagues [32, 35, 36] play a major role in the introduction of alternative measures to author affiliations in order to assess internationality (e.g., the composition of editorial boards, the publisher of the journal, the prevalence of international collaborations and comparative research etc.). Furthermore, their results seem to blatantly oppose the fact that most 
journals in the fields of criminology and criminal justice (61.9\% of 551 examined) self-identify as either international or comparative [34].

Following these indications, a recent study by Faraldo-Cabana and Lamela [26] examined ten Q1 (Scimago Journal Ranking,Law) self-proclaimed international journals to assess the actual levels of their internationalization as conceptualized via three basic criteria: diversity within the editorial boards, diversity within the authors and data sources, and the prevalence of international co-authorship. Most of the journals were found to have low levels of international involvement, with distinctly high proportions of Anglo-American editorial board members, authors, and data sources. In April 2018, 69.2\% of the 465 board members examined were based in US $(35.7 \%)$ or the UK $(33.5 \%)$. This measure is even higher $(82.2 \%)$ when considering all the countries of the Anglosphere (Australia 6\%; Canada 5.2\%; New Zealand $1.5 \%$; Ireland $0.4 \%$ ). Furthermore, $69.7 \%$ of the 399 articles authored by 798 people and published in 2017 had at least one Anglo-American author, which also means that only $30.3 \%$ of all the publications were written without the involvement of authors from US or the UK. The analysis showed that countries of long legal traditions and with considerable number of scholars and institutions (e.g., China, France, Germany, Italy, or Spain) account less than $1.7 \%$ each for all board members and authors in the examined top outlets of criminology and criminal justice, "values that are rather symbolic, far below the real weight of their current scientific output" [26, p. 166].

Most recently, Messner [37] conducted a content analysis based on all empirically involved articles in Criminology (published between February 2000 and November 2019) and found major disparities. $78.6 \%(n=456)$ of the 580 papers were strictly US-centric (i.e., US-only data and all US authors). His analysis, however, also indicated a clear trend towards greater internationalization with respect to data sources. The proportion of articles based on solely US data seems to steadily decline throughout the years $(87.6 \%$ between 2000 and 2004; 75.6\% between 2015 and 2019). On the other hand, the measures of transnational collaborations in the study do not indicate distinct trends towards internationalization of any sort [37, $\mathrm{p}$. 16].

Messner [37, p. 15] concludes that "prior research would seem to offer no simple answer to the pertinent question of whether internationalization remains nothing more than wishful thinking in criminology". Further analyses, taking stock of any progress to date, are then prompted. Moreover, as indicated above, research should account for alternative measures when assessing internationality, including national diversity across authors and institutions and their scientific influence (as measured via citations), the institutional backgrounds of highly influential journals, and the prevalence and nature of international collaborations (as indicated by patterns of coauthorship). To the best of our knowledge, no comprehensive research available to date offers such assessment of law-related fields in general. Accordingly, we propose the following research questions:

$R Q 1$ What are the publishing trends for Scopus-indexed legal studies journals in the last two decades?

$R Q 2$ What are the publication trends amongst the most prolific legal studies scholars in terms of journal publication? 
Table 1 Publishers' share in Scopus-indexed Law journals in 2020

\begin{tabular}{llc}
\hline Publishers & $\begin{array}{l}\text { Number of } \\
\text { journals }\end{array}$ & Market share (\%) \\
\hline Taylor and Francis & 97 & 11.00 \\
University Presses (all) & 88 & 9.98 \\
Brill & 87 & 9.86 \\
Springer Nature & 67 & 7.60 \\
Oxford University Press & 45 & 5.10 \\
Sage & 40 & 4.54 \\
Cambridge University Press & 30 & 3.40 \\
Wiley-Blackwell & 29 & 3.29 \\
Walter de Gruyter & 23 & 2.61 \\
Elsevier & 22 & 2.49 \\
Emerald & 19 & 2.15 \\
Other publishers & 337 & 38.21 \\
\hline
\end{tabular}

\section{Methods and Results}

In line with our research questions, we analyzed both the publishing trends of Scopus-indexed law journals and the publication patterns of the most prolific legal studies scholars. As our first research question is related to publishing trends in the past two decades, we conducted longitudinal analyses with 2000, 2010 and 2020 as benchmark years.

From Scopus, we exported the list of publishers of those journals that are indexed under the category of Law. Overall, we found 882 publishing houses with at least one Law journal, however, with respect to the great number of publishers, we restricted the analysis for those with at least ten law journals. As Table 1 shows, there are ten publishing houses with more than ten law journals, and their market share, jointly, is over $50 \%$. In other words, three percent $(n=10)$ of all relevant publishers $(n=351)$ owns half of the publication outlets in the field, whilst together with university presses, their share is $62 \%$. The contribution of Taylor \& Francis and Brill is especially significant with circa $10 \%$ share for each.

To see the longitudinal trends of Law journal publications in terms of geographical distribution, we analyzed the publication output, citation count and $\mathrm{H}$-index values of the most productive countries in the benchmark years (Table 2).

Beyond country-level analysis, we also calculated the publication share of different world regions in each benchmark year, together with the share of open access publications (Table 3).

Beyond the analysis of geographical distributions on various levels, we examined the thematic trends of the discipline as it can be measured in SciVal for the last decade (2011-2020). SciVal works with Scopus data, therefore, this part of the study and our previous analyses share the same database. Results show that, there are no institutions from beyond the western world amongst the top 20 most productive institution in the field, whilst only a limited number of non-Western institutions $(n=4)$ make it in the top 100 (Table 4). 
Table 2 Geographical distribution of research production, citation, and H-index in Law journals from 2000-2020

\begin{tabular}{|c|c|c|c|c|}
\hline & Position & Documents & Citations & H-index \\
\hline \multirow[t]{10}{*}{2000} & 1 & US & US & US \\
\hline & 2 & UK & UK & UK \\
\hline & 3 & Germany & Canada & Canada \\
\hline & 4 & Australia & Australia & Australia \\
\hline & 5 & Canada & Netherlands & Netherlands \\
\hline & 6 & Netherlands & Germany & Germany \\
\hline & 7 & France & Sweden & Spain \\
\hline & 8 & Israel & Israel & Italy \\
\hline & 9 & Japan & New Zealand & Taiwan \\
\hline & 10 & Switzerland & Norway & China \\
\hline \multirow[t]{10}{*}{2010} & 1 & US & US & US \\
\hline & 2 & UK & UK & UK \\
\hline & 3 & China & Canada & Canada \\
\hline & 4 & Australia & Australia & Australia \\
\hline & 5 & Canada & Netherlands & Netherlands \\
\hline & 6 & Germany & Germany & Germany \\
\hline & 7 & Netherlands & Spain & Spain \\
\hline & 8 & France & China & Italy \\
\hline & 9 & India & Italy & Taiwan \\
\hline & 10 & Spain & Sweden & China \\
\hline \multirow[t]{10}{*}{2020} & 1 & US & UK & US \\
\hline & 2 & UK & US & UK \\
\hline & 3 & India & China & Canada \\
\hline & 4 & Australia & Australia & Australia \\
\hline & 5 & Spain & Canada & Netherlands \\
\hline & 6 & China & Germany & Germany \\
\hline & 7 & Italy & Netherlands & Spain \\
\hline & 8 & Iraq & Spain & Italy \\
\hline & 9 & Germany & France & Taiwan \\
\hline & 10 & Canada & Italy & China \\
\hline
\end{tabular}

The general country-level patterns of internationalization (Fig. 1) in the last decade indicate an emerging internationalization trend in each country examined, except for Spain, and with the most significant internationalization displayed by French Law scholarship. Here, the level of internationalization is measured by the proportion of journal articles that are coauthored by at least one scholar of a foreign affiliation. Therefore, for instance, Fig. 1 indicates that, in 2020, more than $40 \%$ of papers by French authors were coauthored with scholars from beyond France.

Our second research question was related to the publication trends of the 50 most prolific scholars of the field. Therefore, we downloaded the list of the most prolific legal scholars from SciVal that defines prolificacy by the number of Scopus-indexed publications between 2011 and 2020 within the category of Law. For the network 


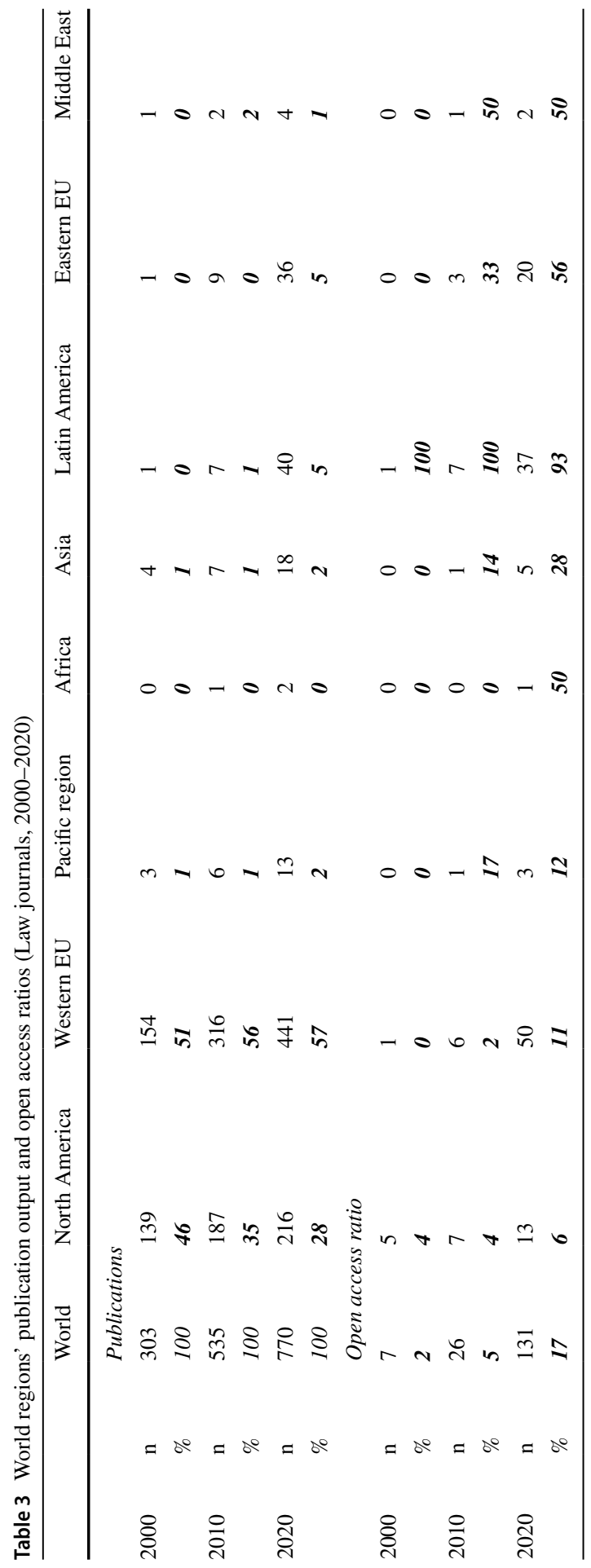


Table 4 Top performing institutions in Scopus Law journals (2011-2020)

\begin{tabular}{|c|c|c|c|}
\hline Position & Country & Institution & Number of papers \\
\hline 1 & US & Harvard University & 1729 \\
\hline 1 & UK & University of Oxford & 1684 \\
\hline 1 & UK & University of Cambridge & 1606 \\
\hline 1 & US & New York University & 1400 \\
\hline 1 & US & Columbia University & 1301 \\
\hline 1 & US & Yale University & 1337 \\
\hline 1 & Australia & University of Melbourne & 1109 \\
\hline 1 & US & University of California at Berkeley & 1015 \\
\hline 1 & Australia & University of New South Wales & 1015 \\
\hline 1 & Netherlands & University of Amsterdam & 1009 \\
\hline 1 & UK & King's College London & 993 \\
\hline 1 & UK & University College London & 961 \\
\hline 1 & US & University of Pennsylvania & 949 \\
\hline 1 & US & Stanford University & 918 \\
\hline 1 & US & The University of Chicago & 902 \\
\hline 1 & Australia & Monash University & 894 \\
\hline 1 & Canada & University of Toronto & 891 \\
\hline 1 & UK & LSE & 882 \\
\hline 1 & US & City University of New York & 878 \\
\hline 1 & US & Duke University & 856 \\
\hline 44 & Singapore & National University of Singapore & 619 \\
\hline 53 & Israel & Hebrew University of Jerusalem & 578 \\
\hline 72 & Hong Kong & The University of Hong Kong & 494 \\
\hline 80 & South Africa & University of Johannesburg & 457 \\
\hline 96 & Brazil & Universidade de São Paulo & 405 \\
\hline
\end{tabular}

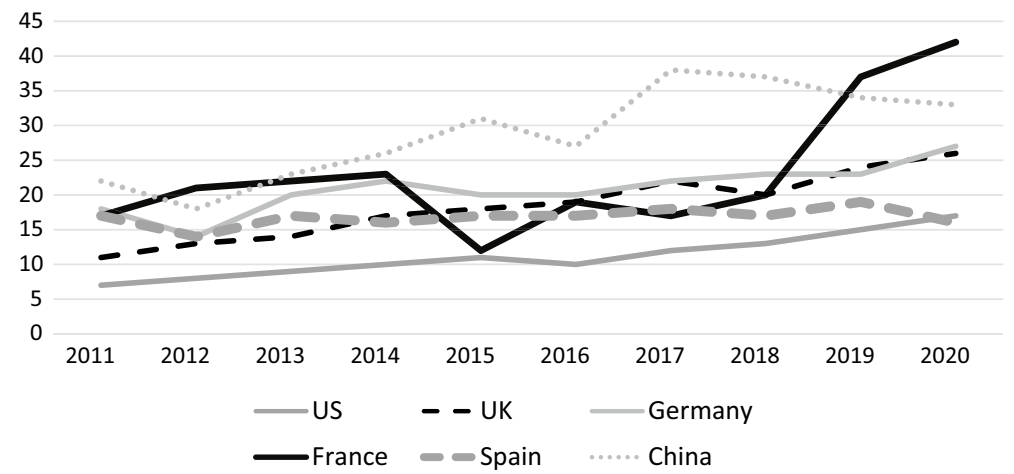

Fig. 1 Country-level internationalization of Scopus-indexed publications in Law (2011-2020) 


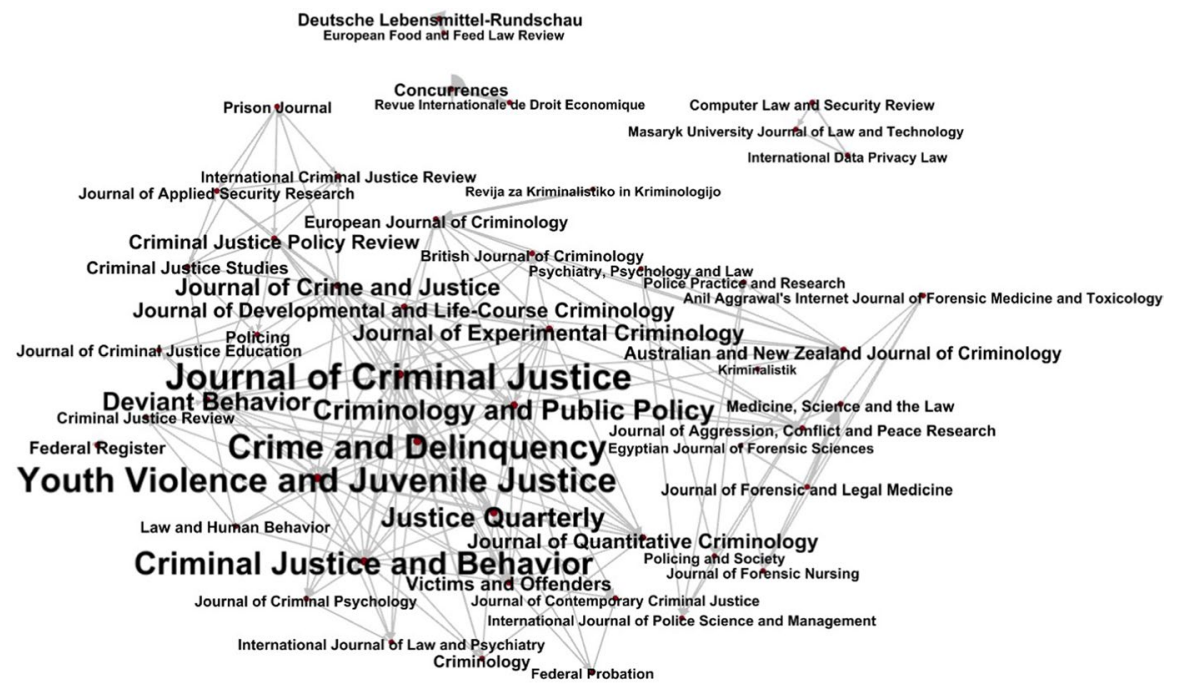

Fig. 2 The publication network of the 50 most prolific scholars in Law (2011-2020). Title size is proportional to the number of papers in the corresponding journal

analysis, we built the database as follows. First, with Scopus, we defined and coded the journals in which our selected scholars published. Journals serve as the vertices of our network. Second, for each scholar, we connected those journals in which the scholar published their papers. These connections serve as the edges of the network. As a results, we get the publication networks of our selected researchers. After, we merged the individual-level networks to a single network that contains the publication trends of all 50 scholars aggregately. The database was imported to Gephi, an open-source network analysis and visualization software. For better readability, we cleansed the data and calculated only with journals with at least two publications from a given author.

Based on our network, we investigated which journals were the most popular amongst our selected scholars and analyzed country-level collaborations between the most productive researchers. As Fig. 2 indicates, journals with a focus on criminal justice and deviant behavior were the most popular amongst these scholars with Youth Violence and Juvenile Justice at the leading position.

We also analyzed the level of internationalization, and we found country-level hubs in the network with detached subgraphs for French and German scholars, and semi-detached graphs for scholars from the US and the UK (Figs. 3 and 4).

Finally, we built the network of international co-authorships for the analyzed Law scholars as follows. For all the papers, that the 50 most prolific scholars published between 2011 and 2020, we coded the country of affiliations of all co-authors. Therefore, countries serve as the vertices of the network, while edges are represented by connecting the countries of the coauthors (Fig. 5). For better readability, we cleansed the data and calculated only with those countries where the number of coauthors was at least five. 


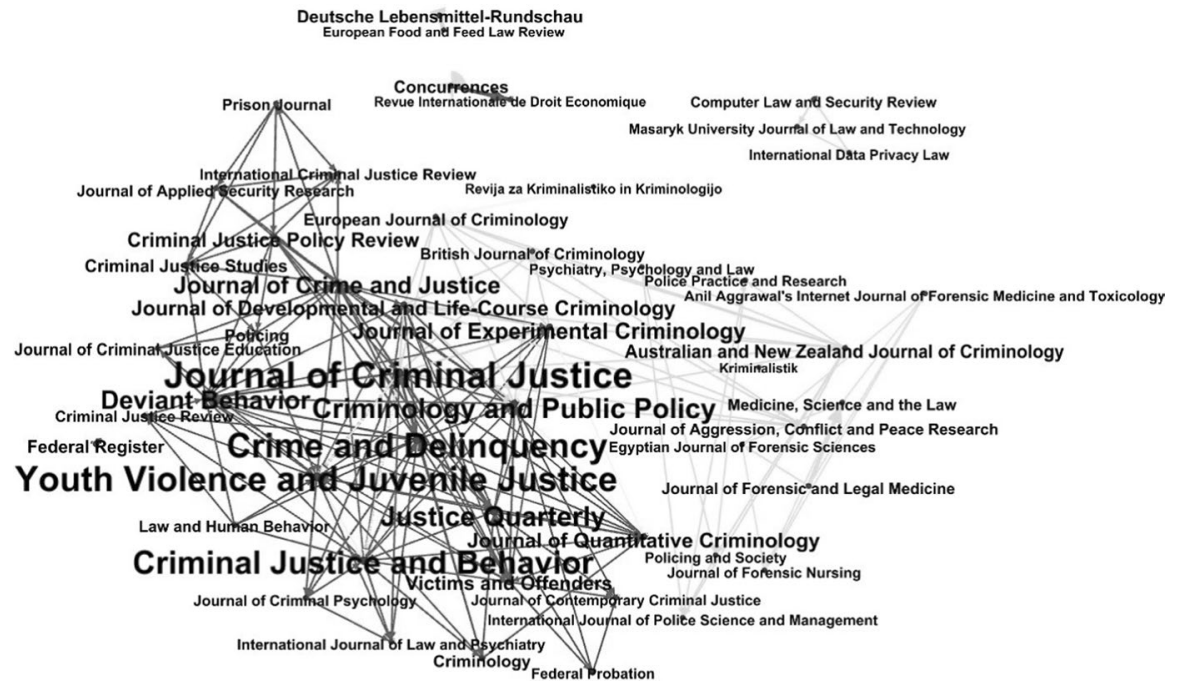

Fig. 3 The publication network of the most prolific US authors (highlighted) in Law (2011-2020). Title size is proportional to the number of papers in the corresponding journal

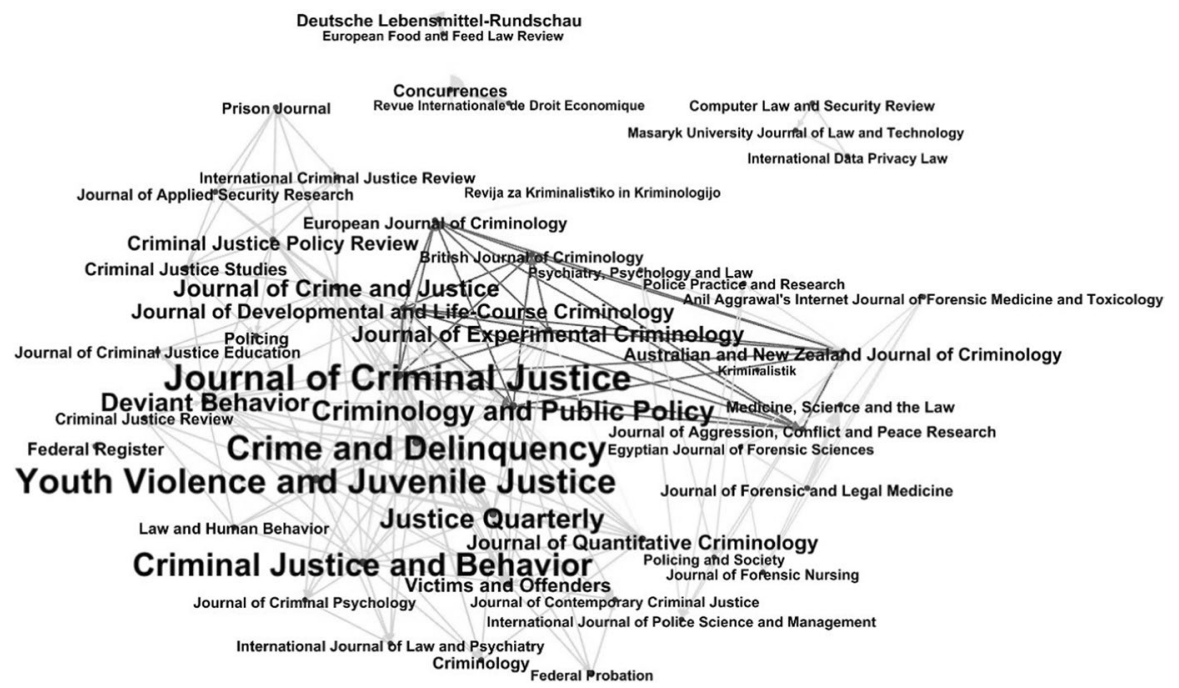

Fig. 4 The publication network of the most prolific UK authors (highlighted) in Law (2011-2020). Title size is proportional to the number of papers in the corresponding journal

\section{Discussion}

Although scholarly analysis of journal publication trends is an emerging area of research [29, 31, 35], we have limited knowledge on how publication trends evolved within the field of law, especially concerning the processes of internationalization 


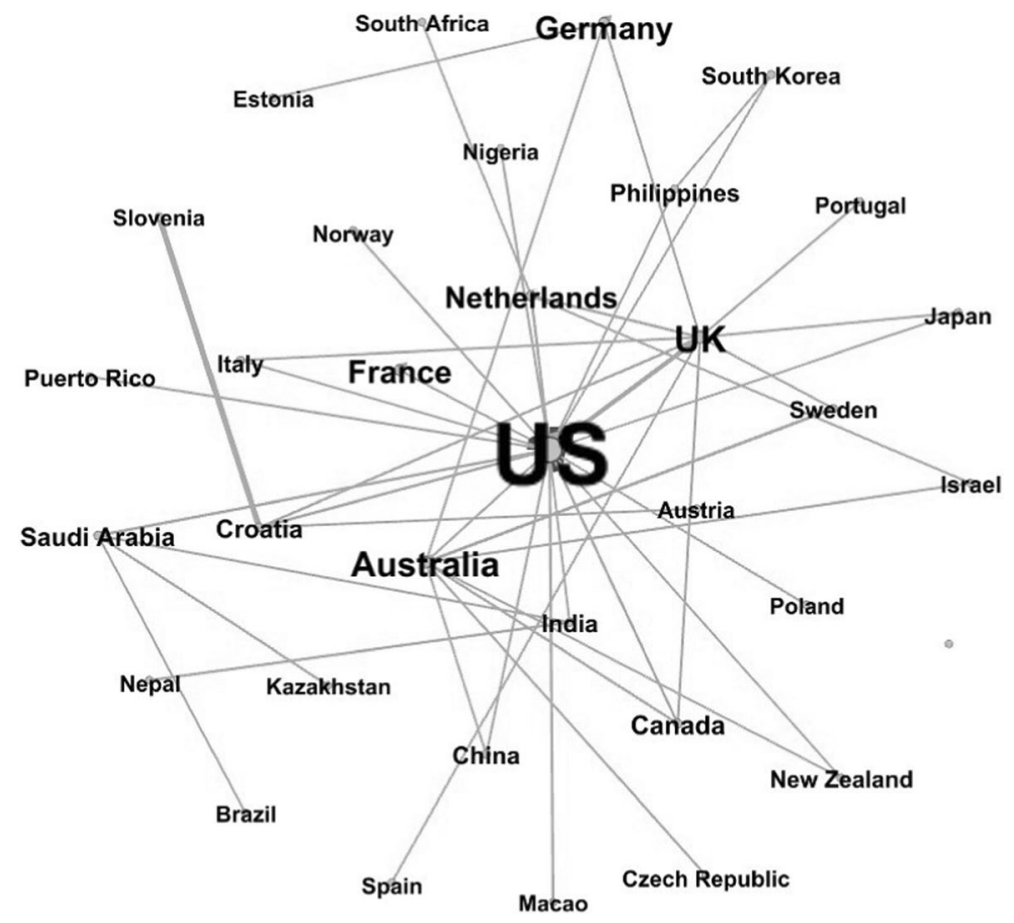

Fig. 5 Country-level collaboration of the 50 most prolific scholars in Law (2011-2020). Title size is proportional to the number of papers written by the authors of the corresponding country

$[1,5,8,11,12,30,38,39,50]$. Our analysis, therefore, aims to contribute to our knowledge on how legal studies, as a scholarly field, changed in the past two decades in terms of publications in Scopus-indexed sources.

Our first finding is that, while the market is mostly concentrated in the hands of giant publishing houses, university presses still have a significant presence with circa $10 \%$ market share. Moreover, while, according to the literature, legal research is usually considered a field in which international journal publications are less relevant than in other social sciences [26], there are still a significant number of Scopus indexed Law journals ( $\mathrm{n}=770$ in 2020). In fact, the number of Law journals exceeds the number of journals in many other fields, including communication $(n=508)$, economics $(n=677)$, and political science $(n=573)$. In conclusion, our analysis shows that Scopus journals in Law constitute an established field with a considerable number of periodicals, published by both prestigious international publishing houses and a legion of university presses.

There are significant differences between the performance of different countries and world regions. Similarly to other disciplines [19, 28], the United States seem to occupy the first position in all benchmark years and in all scientometric measurements: US authors publish the most papers, get the most citations and have the highest $\mathrm{H}$-indices. Our results confirm those of former studies, that found significant Anglo-American dominances in the field of legal studies 
$[15,25]$. Moreover, the advantage of countries with native English is especially stressed in the case of citations. While countries with strong academic culture in Law-France and Germany, for instance-publish a lot of papers, their citation counts fall far behind those of English-speaking countries. This could indicate that although international visibility (as expressed by the number of publications) might be obtained in national languages, publishing in English is necessary for international impact (as measured via citation count and H-index). In other words, an increasing number of publications can only predict increased impact in the future if the language of these publications is English. One characteristic example here is China, that-in the 2010s - started to publish a lot internationally in English, and, as a result, Chinese authors currently hold the third position in overall citation rankings in 2020, overtaking even some English-speaking countries (e.g., Australia, Canada). Finally, our analysis indicates that $\mathrm{H}$-index is the most constant variable as the country-level $\mathrm{H}$-indices in legal studies have not changed in the past two decades in any significant manner.

In terms of business models, we found an open access ratio that is comparable with other research fields. Demeter, Jele and Major [21] analyzed ten disciplines in terms of business models and found that although in most research fields the share of open access journals was under 5\% in 2000, this number improved to $12-20 \%$ by 2020. We observed similar prevalence of open access in legal studies (the proportion of open access journals is $17 \%$ in 2020). In terms of geographical differences, the trend corresponds to the observations of previous studies: the open access model is most typical in Latin America (93\%), followed by other non-Western regions, while we see small proportions of open access journals in Western Europe (11\%) and in the United States $(6 \%)$. These trends indicate, once again, that the publishing industry in the field Law is well interbedded in the global industry, and publication trends of the discipline follow global trends in terms of both geographical distributions and business models.

Unsurprisingly, amongst the top 20 most productive institutions, there are mostly North American $(n=10)$ and British universities $(n=5)$, with the triumvirate of Harvard, Oxford, and Cambridge on the top. Moreover, all the top 20 institutions are in countries with the official language of English, except for the University of Amsterdam in the Netherlands. However, as English is compulsory at all levels of the Dutch secondary education system, language-besides other factors-appears to be a decisive factor in international publication success in Law journals, too. On the top 100 list, there are several non-Western universities, however, they are typically well embedded in Anglo-Saxon international research networks, such as the Hebrew University of Jerusalem or the National University of Singapore. In consonance with the linguistic hegemony of English-speaking countries, the level of internationalization is the lowest in the case of countries with native English. In 2011, the UK and the US appeared to be the two least internationalized countries examined, and while there was a significant improvement in the case of the former, the US still appears to be heavily isolated amongst the top performers. Results indicate that countries with strong national academic culture in legal studies, such as France and Germany, started to distinctly internationalize in the last decade, and consequently, in 
2020, French papers were the most international in terms of the amount of internationally coauthored papers. Furthermore, despite a minor decline in the last three years, China remains one of the most prominent international publishers in Law in 2020.

Our second research question related to the publication patterns of the most productive scholars. We examined the network of popular journals amongst these scholars and indicated the central outlets in which prominent Law scholars tend to publish a lot. Based on our findings, we can define three types of network development. First, thematic clusters are engendering around "hot topics". In our case, the main thematic cluster is naturally crime and violence: the most popular journals-Journal of Crime Justice, Crime and Delinquency, Youth Violence and Juvenile Justice, Justice Quarterly and Criminal Justice and Behavior-form a relatively tight core network, extended by a looser network of related journals with less publication output. Furthermore, we also detected a detached hub with a focus on law and technology. These findings confirm and slightly extend the results of former research that also concluded that criminology journals are the most prevalent publication outlets amongst legal studies researchers.

Second, we found a detectable linguistic differentiation of French and German authors that publish a significant number of papers, but, typically, in the same national journals. While these journals are indexed in Scopus, they are written in national languages and so international scholars do not typically publish in them. These journals are detached from the publication networks and papers published in these periodicals are typically undercited. Finally, the third kind of clustering can be detected on the level of countries. Results show that American scholars tend to publish in a typical set of journals, and so do British, French, and German authors. In other words, the geographic composition of authorship of the journals is not balanced: we have a distinctive American and a distinctive British hub, while French and German authors also form their own publication communities.

These latter findings led us to the analysis of the most prolific Law scholars' international collaboration networks. Our results indicate that international collaboration, in general, is relatively low with a limited set of edges between different countries. In the case of the most productive countries-that is, the US and the UK-self-loops are quite frequent, which means that even in the case of coauthored papers, coauthors most likely are affiliated in the same country. Linguistic determination is extremely strong in this level, too: native English countries (i.e., the US, the UK, Canada, and Australia) regularly cooperate with each other, while other countries' outputs lack similar international diversities. Notwithstanding, the most productive scholars seem to have a tendency of working on an international level, as-except for a few scholars from France and Germany-most scholars published at least some international papers. Nonetheless, as the high number of American self-loops indicates, internationalization does not appear to be very important for American Law scholars. The central position of the US in the network is a result following the efforts of scholars from other countries as they strive for collaborations with American scholars. 


\section{Conclusions}

Our study showed that, in the system of international academic publishing, Law research should be considered a well-established field with a clear fit to international trends. The field is highly concentrated around a set of international publishers and university presses with strong ties towards the Western world-that is, typically the US and the UK. Furthermore, the amount of open access publications has been constantly growing in the past two decades, but the pace of growth is significantly lower in North America and the UK than in the more peripheric world regions. The level of internationalization is also rising over time; however, the most productive scholars are less international than it is expected.

In sum, the field of Law journal publishing follows the global trends in terms of market share and geographical distribution, but the level of internationalization is relatively low with infrequent international collaborations, a strong hegemony of English-speaking countries, and a clear tendency to develop linguistic, geographic, and thematic clusters. As a conclusion, we point towards the fact that, while the need for the internationalization of legal studies is a subject of intense scholarly discussion, the implementation of internationalization goals is yet to be realized. Further efforts are prompted to enhance geographical diversity and increase the level of international collaboration; to avoid isolationism in the science of law.

Funding Open access funding provided by National University of Public Service.

Open Access This article is licensed under a Creative Commons Attribution 4.0 International License, which permits use, sharing, adaptation, distribution and reproduction in any medium or format, as long as you give appropriate credit to the original author(s) and the source, provide a link to the Creative Commons licence, and indicate if changes were made. The images or other third party material in this article are included in the article's Creative Commons licence, unless indicated otherwise in a credit line to the material. If material is not included in the article's Creative Commons licence and your intended use is not permitted by statutory regulation or exceeds the permitted use, you will need to obtain permission directly from the copyright holder. To view a copy of this licence, visit http://creativecommons.org/licen ses/by/4.0/.

\section{References}

1. Aas KF. 'The Earth is one but the world is not': Criminological theory and its geopolitical divisions. Theor Criminol. 2012;16(1):5-20. https://doi.org/10.1177/1362480611433433.

2. Adair JG, Coêlho AEL, Luna JR. How international is psychology? Int J Psychol. 2002;37(3):16070. https://doi.org/10.1080/00207590143000351.

3. Adler F. A note on teaching “international.” J Crim Justice Edu. 1996;7(2):223-5. https://doi.org/10. 1080/10511259600096071.

4. Bański J, Ferenc M. "International" or "Anglo-American" journals of geography? Geoforum. 2013;45:285-95. https://doi.org/10.1016/j.geoforum.2012.11.016.

5. Barberet R. The internationalization of criminology? A content analysis of presentations at american society of criminology conferences. J Crim Just Edu. 2007;18(3):406-27. https://doi.org/10. 1080/10511250701705362. 
6. Bennett RR. Comparative criminology and criminal justice research: the state of our knowledge. Just Q. 2004;21(1):1-21. https://doi.org/10.1080/07418820400095721.

7. Bennett RR. Comparative Criminological and criminal justice research and the data that drive them. Int J Comp Appl Crim Just. 2009;33(2):171-92. https://doi.org/10.1080/01924036.2009.9678804.

8. Birkbeck C. Imprisonment and internment: comparing penal institutions North and South. Punishment Soc. 2011;13(3):307-32. https://doi.org/10.1177/1462474511404320.

9. Blackmur, D. (2007). The public regulation of higher education qualities: rationale, processes, and outcomes. In DF Westerheijden, B Stensaker, MJ Rosa (Eds.), Quality Assurance in Higher Education: Trends in Regulation, Translation and Transformation (pp. 15-45). Springer, Cham. https:// doi.org/10.1007/978-1-4020-6012-0_1

10. Buela-Casal G, Perakakis P, Taylor M, Checa P. Measuring internationality: reflections and perspectives on academic journals. Scientometrics. 2006;67(1):45-65. https://doi.org/10.1007/ s11192-006-0050-z.

11. Carrington, K., Hogg, R., Scott, J., \& Sozzo, M. (2018). Criminology, southern theory and cognitive justice. In: K. Carrington, R. Hogg, J. Scott, \& M. Sozzo (Eds.), The Palgrave handbook of criminology and the global south (pp. 3-17). Springer, Berlin. https://doi.org/10.1007/978-3-319-65021-0_1

12. Carrington K, Hogg R, Sozzo M. Southern criminology. Br J Criminol. 2016;56(1):1-20. https:// doi.org/10.1093/bjc/azv083.

13. Cohn EG, Farrington DP. Who are the most-cited scholars in major American criminology and criminal justice journals? J Crim Just. 1994;22(6):517-34. https://doi.org/10.1016/0047-2352(94) 90093-0.

14. Cohn EG, Farrington DP. Assessing the quality of American doctoral program faculty in criminology and criminal justice, 1991-1995. J Crim Just Educ. 1998;9(2):187-210. https://doi.org/10.1080/ 10511259800084281.

15. Cohn EG, Farrington DP. Changes in the most-cited scholars in twenty criminology and criminal justice journals between 1990 and 1995. J Crim Just. 1999;27(4):345-59. https://doi.org/10.1016/ S0047-2352(99)00006-9.

16. Cohn EG, Iratzoqui A. The most cited scholars in five international criminology journals, 2006-10. Br J Criminol. 2016;56(3):602-23. https://doi.org/10.1093/bjc/azv048.

17. Connell R. Northern theory: the political geography of general social theory. Theory Soc. 2006;35(2):237-64. https://doi.org/10.1007/s11186-006-9004-y.

18. Connell, R. (2007). Southern Theory: The global dynamics of knowledge in social science. Routledge.

19. Demeter M. The world-systemic dynamics of knowledge production: the distribution of transnational academic capital in the social sciences. J World-Syst Res. 2019;25(1):111-44. https://doi.org/ 10.5195/jwsr.2019.887.

20. Demeter M. Academic knowledge production and the global south: questioning inequality and under-representation. Springer International Publishing. 2020. https://doi.org/10.1007/ 978-3-030-52701-3.

21. Demeter M, Jele Á, Major Zs. The international development of open access publishing: a comparative empirical analysis over seven world regions and nine academic disciplines. Pub Res Q. 2021;37:364-83. https://doi.org/10.1007/s12109-021-09814-9.

22. Dobbins M, Knill C. Higher Education Governance and Policy Change in Western Europe. Basingstoke: Palgrave Macmillan; 2014.

23. Dyachenko EL. Internationalization of academic journals: Is there still a gap between social and natural sciences? Scientometrics. 2014;101(1):241-55. https://doi.org/10.1007/s11192-014-1357-9.

24. Fabianic D. Institutional affiliation of authors in selected criminal justice journals. J Crim Just. 1981;9(3):247-52. https://doi.org/10.1016/0047-2352(81)90074-X.

25. Fabianic D. Educational backgrounds of most-cited scholars. J Crim Just. 1999;27(6):517-24. https://doi.org/10.1016/S0047-2352(99)00022-7.

26. Faraldo-Cabana P, Lamela C. How international are the top international journals of criminology and criminal justice? Eur J Crim Policy Res. 2021;27(2):151-74. https://doi.org/10.1007/ s10610-019-09426-2.

27. Gutiérrez J, López-Nieva P. Are international journals of human geography really international? Prog Hum Geogr. 2001;25(1):53-69. https://doi.org/10.1191/030913201666823316.

28. Ha L. Olympic champions and successful scholars. J Mass Commun Q. 2016;93(4):725-7.

29. Harzing AW, Metz I. Practicing what we preach: the geographic diversity of editorial boards. Manag Int Rev. 2013;53(2):169-87. https://doi.org/10.1007/s11575-011-0124-X. 
30. Hogg R, Scott J, Sozzo M. Southern criminology: guest editors' introduction. Int J Crime Justice Soc Democr. 2017;6(1):1-7. https://doi.org/10.5204/ijcjsd.v6i1.395.

31. Iefremova O, Sas D, Kozak M. International collaboration among authors of. Curr Sci. 2016;110(8):6.

32. Kim B, Lin W-CA, Lambert EG. Comparative/international research on juvenile justice issues: a review of juvenile justice specialty journals. J Crim Justce Edu. 2015;26(4):545-62. https://doi.org/ 10.1080/10511253.2015.1079330.

33. Kim B, Merlo AV. An examination of international or comparative studies under the aegis of the ESC. Criminol Eur. 2011;11(3):6-7.

34. Kim B, Merlo AV, Lin A, Kruis N (2016) Publication options for international/comparative scholars: exploring criminology and criminal justice journals. Annual meeting of the European Society of Criminology, Munster

35. Kim B, Merlo AV, Seo C. Internationality of women specialty journals: content analysis and survey of editors. Asian J Criminol. 2018;13(3):231-49. https://doi.org/10.1007/s11417-018-9268-y.

36. Kim B., Wan-Chun Lin, A., \& Lambert, E. (2014). Research on policing in East Asia: A review of SSCI policing specialty journals. Policing: An International Journal of Police Strategies \& Management, 37(3): 612-629. https://doi.org/10.1108/PIJPSM-01-2014-0009

37. Messner SF. The glass is at least half full: reflections on the internationalization of criminology. Int Criminol. 2021;1(1):13-9. https://doi.org/10.1007/s43576-020-00001-y.

38. Moosavi L. A friendly critique of 'Asian criminology' and 'Southern criminology.' Br J Criminol. 2019;59(2):257-75. https://doi.org/10.1093/bjc/azy045.

39. Moosavi L. Decolonising criminology: Syed Hussein Alatas on crimes of the powerful. Crit Criminol. 2019;27(2):229-42. https://doi.org/10.1007/s10612-018-9396-9.

40. Ravanides C. The internationalization of the American Journal of International law: reality or Chimera (a survey). Hastings Int Comp Law Rev. 2008;31(1):193-250.

41. Reichel P. Comparative criminal justice systems: a topical approach. 7th ed. London: Pearson; 2017.

42. Santos BS editor. Another knowledge is possible: beyond northern epistemologies. Brooklyn: Verso Books; 2008.

43. Shapiro FR. Origins of bibliometrics, citation indexing, and citation analysis: the neglected legal literature. J Am Soc Inf Sci. 1992;43(5):337-9. https://doi.org/10.1002/(SICI)1097-4571(199206) 43:5\%3c337::AID-ASI2\%3e3.0.CO;2-T.

44. Shapiro FR. The most-cited legal scholars. J Leg Stud. 2000;29(S1):409-26. https://doi.org/10. $1086 / 468080$.

45. Sorensen J. Scholarly productivity in criminal justice: Institutional affiliation of authors in the top ten criminal justice journals. J Crim Just. 1994;22(6):535-47. https://doi.org/10.1016/00472352(94)90094-9.

46. Sorensen J, Pilgrim R. The institutional affiliations of authors in leading criminology and criminal justice journals. J Crim Just. 2002;30(1):11-8. https://doi.org/10.1016/S0047-2352(01)00118-0.

47. Taggart WA, Holmes MD. Institutional productivity in criminal justice and criminology: an examination of author affiliation in selected journals. J Crim Just. 1991;19(6):549-61. https://doi.org/10. 1016/0047-2352(91)90066-5.

48. Uzun A. Assessing internationality of scholarly journals through foreign authorship patterns: the case of major journals in information science, and scientometrics. Scientometrics. 2004;61(3):45765. https://doi.org/10.1023/B:SCIE.0000045121.26810.35.

49. Wright RA, Cohn EG. Most-cited scholars in criminal justice textbooks, 1989-1993. J Crim Just. 1996;24(5):459-67.

50. Zimring FE. The necessity and value of transnational comparative study: Some preaching from a recent convert. Criminol Public Policy. 2006;5(4):615-22. https://doi.org/10.1111/j.1745-9133. 2006.00407.x.

Publisher's Note Springer Nature remains neutral with regard to jurisdictional claims in published maps and institutional affiliations. 